Cite this: NewJ.Chem., 2013,

37, 152

Received (in Montpellier, France)

15th August 2012,

Accepted 4th October 2012

DOI: $10.1039 / c 2 n j 40728 k$

www.rsc.org/njc

\section{Carbon NMR investigation of the polybenzimidazole-dimethylacetamide interactions in membranes for fuel cells}

\author{
Fosca Conti, ${ }^{\text {ab }}$ Sabine Willbold ${ }^{\mathrm{c}}$ Stefano Mammi, ${ }^{\mathrm{b}}$ Carsten Korte, ${ }^{\mathrm{a}}$ \\ Werner Lehnert ${ }^{\text {ad }}$ and Detlef Stolten ${ }^{\text {ad }}$
}

Polybenzimidazole dissolved in dimethylacetamide has been studied by ${ }^{1} \mathrm{H}$ and ${ }^{13} \mathrm{C}$ one and two dimensional NMR methods to investigate the polymer-solvent interactions. The resonance signals have been fully assigned, giving a complete picture of the present species and allowing a study of the involved dynamic processes. The results have been correlated with the formation of $\mathrm{H}$-bonds, and with the presence of tautomeric processes in the polymer.

One fundamental component of a fuel cell (FC) is the electrolyte, which separates the electrocatalytic active sites of cathodes and anodes. Polymer Electrolyte Membrane FCs (PEMFCs) based on Nafion or other perfluorosulphonated polymers are extensively used, although with two main limitations: the high cost and the necessity to fully hydrate the membranes to keep the proton conductivity high. ${ }^{1,2}$ This limits the working temperature to below ca. $100{ }^{\circ} \mathrm{C}$ at ambient pressure, because the membrane dehydrates and the conductivity decays sharply above this temperature. However, recent developments on self-humidifying polymer electrolyte membranes using highly dispersed nanometer-sized Pt and/or metal oxides provide promising results in this respect. ${ }^{3,4}$ High working temperatures would benefit PEMFC performance because of a higher $\mathrm{CO}$ tolerance, faster electrode kinetics and the existence of residual heat useful for energy cogeneration.,

In the last few decades, many non-fluorinated polymeric membrane materials have been considered as alternatives to Nafion. ${ }^{7}$ Acid-doped poly(2,2'-( $m$-phenylene)-5,5'-bibenzimidazole) (PBI) has been studied as a system to be used in High Temperature

\footnotetext{
${ }^{a}$ Institute of Energy and Climate Research - Electrochemical Process Engineering (IEK-3), Forschungszentrum Jülich GmbH, 52425 Jülich, Germany. E-mail:f.conti@fz-juelich.de; Fax: +49 2461 616695; Tel: +49 2461619568

${ }^{b}$ Department of Chemical Sciences, University of Padova, Via Marzolo 1, 35131 Padova, Italy. E-mail: fosca.conti@unipd.it; Fax: +39049 8275829; Tel: +390498275118

${ }^{c}$ Central Division of Analytical Chemistry (ZCH), Forschungszentrum Jülich GmbH, 52425 Jülich, Germany

${ }^{d}$ Mechanical Engineering Faculty, RWTH Aachen University, Germany
}

Polymer Electrolyte Membrane FCs (HT-PEMFCs). It can be used at temperatures as high as $200{ }^{\circ} \mathrm{C}$ without humidification. ${ }^{8-13} \mathrm{PBI}$ is a polymer containing a basic functionality that allows the uptake of acid, which is responsible, and required, for proton conduction (see Fig. 1a for the chemical structure of the repeating unit). The formation of dynamic hydrogen bonding networks, in which protons can readily transfer by hydrogen bond breaking and forming processes, seems to be the determining step for high proton conduction. $^{9}$

Various approaches have been attempted so far to characterize the membrane. Very recently Sannigrahi et al. have demonstrated the existence of the hydrogen bonding network in a PBI gel membrane using FT-IR, Raman, NMR and X-ray structural analysis. ${ }^{14}$

(a)<smiles>Cc1cccc(-c2nc3ccc(-c4ccc5nc(C)n(C)c5c4)cc3n2[Tl])c1</smiles>

(b)

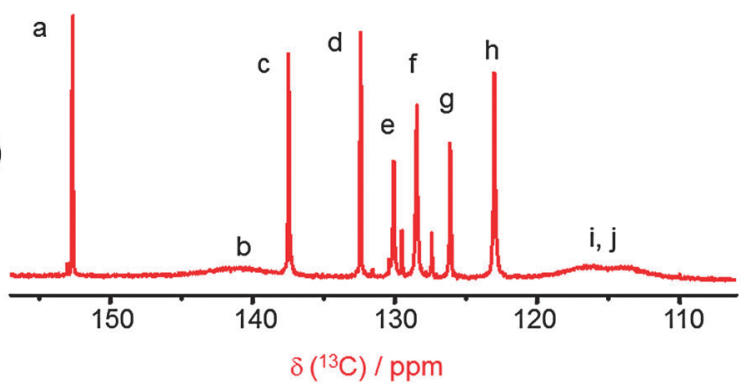

Fig. 1 (a) Chemical structure of the repeating units of polybenzimidazole, PBI, and peak assignment. (b) One-dimensional ${ }^{13} \mathrm{C}$ NMR spectrum of PBI in DMAc. The spectrum is recorded at $70{ }^{\circ} \mathrm{C}$ using $\mathrm{D}_{2} \mathrm{O}$ as reference. Unlabeled NMR peaks are side products. See Table 1 for the chemical shift assignment of the NMR resonances. 
Most recently we have shown the use of Raman spectroscopy as a tool to study PBI-type polymers. ${ }^{15}$

${ }^{1} \mathrm{H}-\mathrm{NMR}$ spectra have been extensively used to elucidate the interaction of PBI with solvents. ${ }^{16-19}$ In particular, during the last few decades, the ${ }^{31} \mathrm{P}$ and ${ }^{1} \mathrm{H}$-NMR resonances have been analysed to explain the mass transport processes in phosphoric acid-doped PBI and to investigate the unresolved question of the dominating proton conduction mechanism. ${ }^{20-25}$

In the present study, for the first time to the best of our knowledge, we report a ${ }^{13} \mathrm{C}-\mathrm{NMR}$ characterization of polybenzimidazole dissolved in dimethylacetamide. Using heteronuclear 2D-NMR experiments, we correlated the ${ }^{13} \mathrm{C}$ signals with those of the protons and we obtained detailed and complete peak assignment. This information is of fundamental importance to understand the structure of the polymer and its interaction with polar solvents, which form the necessary hydrogen bonds for proton conduction in fuel cells.

The ${ }^{13} \mathrm{C}$ 1D-NMR spectrum of polybenzimidazole dissolved in DMeAc is shown in Fig. 1b along with the chemical structure of the repeating units of PBI and the peak assignment.

Proton NMR spectra of a series of pyridine-based polybenzimidazole homo- and random-copolymers have been recently recorded by Sannigrahi et al. They have reported detailed spectral analysis to establish the polymer structure. ${ }^{16}$ Previously, they have reported the proton NMR spectrum of PBI in DMSO- $d_{6}{ }^{17}$ which is consistent with the earlier reports. ${ }^{19,26}$ In addition to their conclusions, we consider the NMR signals of a series of phenylbenzimidazole monomeric compounds differently substituted by halogens and methyl groups. ${ }^{27}$ On the basis of these data, we tried a tentative assignment of our ${ }^{13} \mathrm{C}$-NMR signals. In Fig. 2 a representative ${ }^{1} \mathrm{H}$-NMR spectrum of PBI in DMeAc is presented.

To confirm our assignments and for a more detailed spectral analysis, we performed a series of two dimensional NMR experiments on PBI dissolved in DMAc. In Fig. 3a, the Heteronuclear Single Quantum Coherence (HSQC) spectrum of PBI is reported. Each cross peak represents a bonded $\mathrm{C}-\mathrm{H}$ pair, with its two coordinates related to the chemical shift of the corresponding $\mathrm{H}$ and $\mathrm{C}$ atoms. Moreover, we used a homonuclear correlation spectroscopy (COSY) experiment to identify ${ }^{1} \mathrm{H}$ spins coupled to each other. Fig. 3b shows the COSY spectrum of PBI. Due to magnetization transfer phenomena, cross peaks appear off diagonal. Finally, to

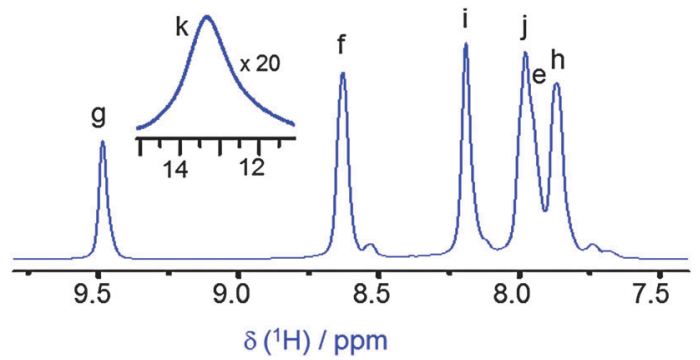

Fig. 2 One-dimensional ${ }^{1} \mathrm{H}-\mathrm{NMR}$ spectrum of $\mathrm{PBI}$ in DMeAc. The inset shows the $\mathrm{H}_{k}$ resonance signal at about $13 \mathrm{ppm}$, the peak height scaled up by a factor of 20 . The spectrum is recorded at $70{ }^{\circ} \mathrm{C}$ using $\mathrm{D}_{2} \mathrm{O}$ as reference. The atom labelling is related to the chemical structure reported in Fig. 1a. See Table 1 for the chemical shift assignment of the NMR resonances. (a)

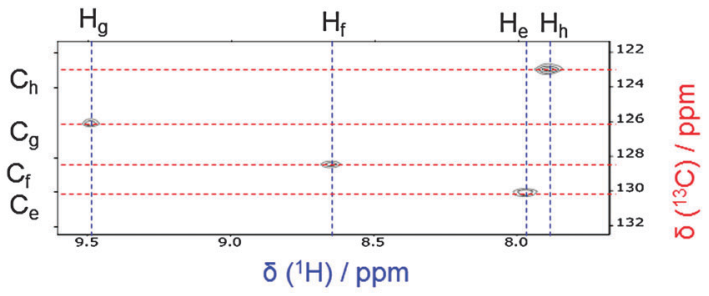

(b)

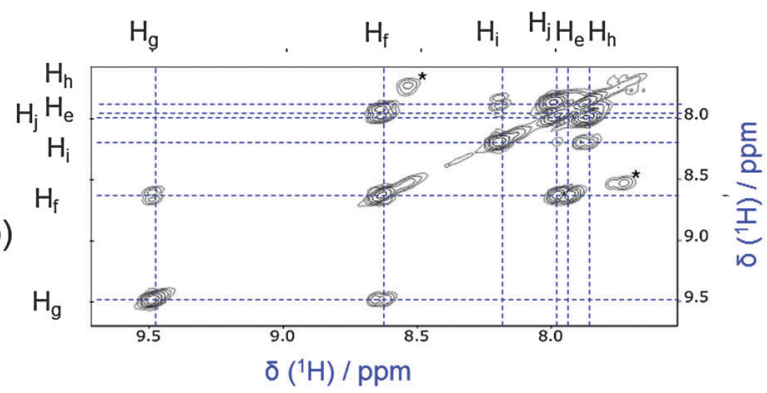

(c)

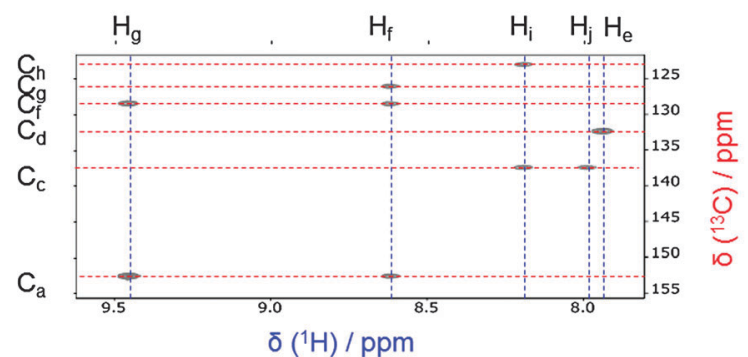

Fig. 3 Parts of two-dimensional NMR spectra of PBI in DMAc at $70{ }^{\circ} \mathrm{C}$. (a) ${ }^{1} \mathrm{H}-{ }^{13} \mathrm{C}$ HSQC spectrum. (b) ${ }^{1} \mathrm{H}-{ }^{1} \mathrm{H}$ COSY spectrum. (c) ${ }^{1} \mathrm{H}-{ }^{13} \mathrm{C}$ HMBC spectrum. Signals marked by a star are side products.

Table $1{ }^{1} \mathrm{H}$ and ${ }^{13} \mathrm{C}$ NMR chemical shifts $\delta$ (ppm) for polybenzimidazole dissolved in dimethylacetamide at $70^{\circ} \mathrm{C}$

\begin{tabular}{lll}
\hline Atom $^{a}$ & $\delta\left({ }^{13} \mathrm{C}\right)$ & $\delta\left({ }^{1} \mathrm{H}\right)^{c}$ \\
\hline $\mathrm{a}$ & 152.5 & - \\
$\mathrm{b}$ & $141(\mathrm{br})^{b}$ & - \\
$\mathrm{c}$ & 137.5 & - \\
$\mathrm{d}$ & 132.4 & $7.94(1 \mathrm{H})$ \\
$\mathrm{e}$ & 130.1 & $8.63(2 \mathrm{H})$ \\
$\mathrm{f}$ & 128.5 & $9.51(1 \mathrm{H})$ \\
$\mathrm{g}$ & 126.1 & $7.87(2 \mathrm{H})$ \\
$\mathrm{h}$ & 123.0 & $8.20(2 \mathrm{H})$ \\
$\mathrm{i}$ & $114,116(\mathrm{br})^{b}$ & $7.99(2 \mathrm{H})$ \\
$\mathrm{j}$ & $114,116(\mathrm{br})^{b}$ & $13.3(1 \mathrm{H}, \mathrm{br})^{b}$ \\
$\mathrm{k}$ & - & \\
${ }^{a}$ Atom labeling is related to Fig. $1 \mathrm{a} .{ }^{b}$ br, broad NMR signal. ${ }^{c}$ The \\
number of NMR equivalent protons is indicated in parentheses.
\end{tabular}

detect heteronuclear correlations over longer ranges of about 2-4 bonds, we performed Heteronuclear Multiple-Bond Correlation experiments (HMBC, Fig. 3c). The final peak assignment is summarized in Table 1.

Of particular interest in Fig. 2 is the peak at 13.3 ppm, which we attribute to the imidazole proton $\mathrm{H}_{k}$. From its high chemical shift value some important issues can be derived. The chemical shift depends on variations in the electron distribution around the observed nuclei. In general, ring currents are very significant in determining how much a nucleus is shielded from the 


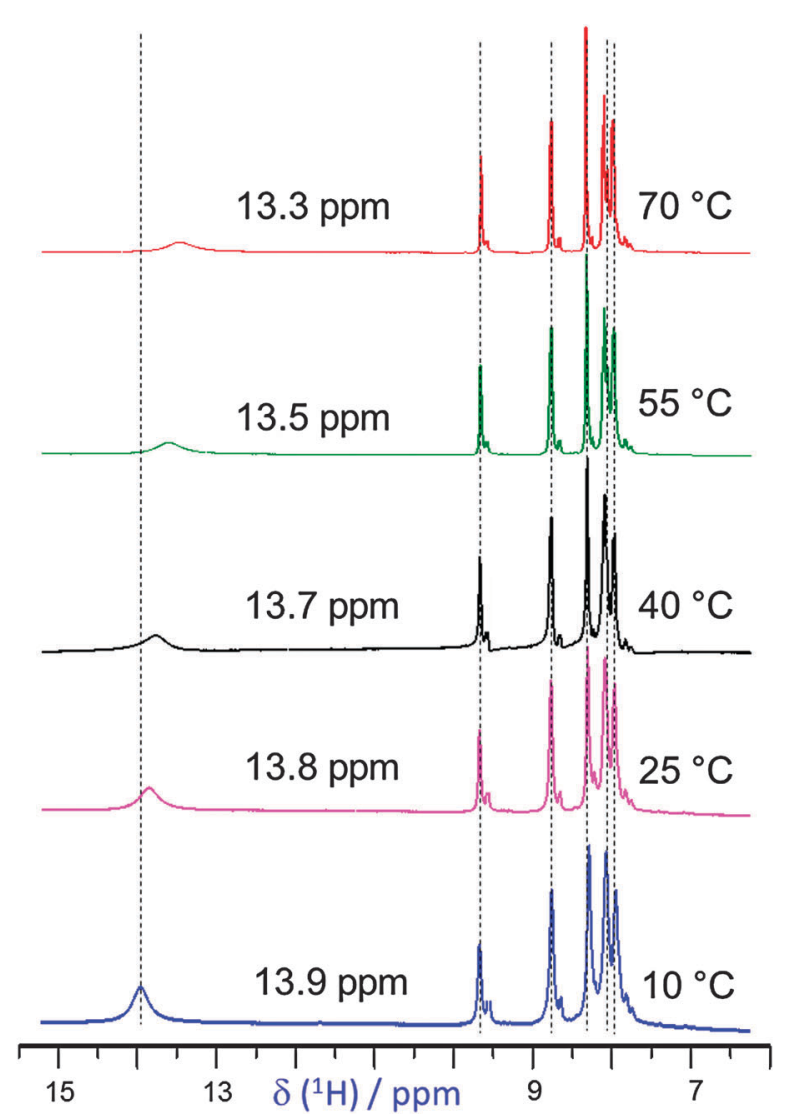

Fig. $4{ }^{1} \mathrm{H}$-NMR spectra of PBI in DMeAc at five different temperatures: 10, 25, 40, 55 , and $70{ }^{\circ} \mathrm{C}$. The spectra are normalized with the peak centered at $8.63 \mathrm{ppm}$. The vertical lines are a help to observe the shift of the ${ }^{1} \mathrm{H}_{k}$ proton at the specified chemical shifts. The other peaks have the same resonance frequency in the whole temperature range.

effects of the external field. The stronger the deshielding effects on the nucleus are, the higher the value of $\delta$ will be. Moreover, the presence of $\mathrm{H}$-bonds has a strong deshielding effect. The chemical shift of the $\mathrm{H}_{k}$ proton of PBI cannot be explained only in terms of ring current effects; H-bonding between PBI chains and between PBI and solvent molecules plays a dominant role. Indeed, it is not uncommon for the chemical shift of hydrogens in molecules to increase by a few ppm by the formation of hydrogen bonds. ${ }^{28}$

The $\mathrm{H}_{k}$ signal shows a very broad line (linewidth at half height $\sim 1.3 \mathrm{ppm})$. As discussed later, we consider an exchange process of the $k$-proton between the two nitrogen sites of the imidazole unit competitive to the formation of hydrogen bonds.

The typical broadened appearance of the $\mathrm{N}-\mathrm{H}$ proton signals can be ascribed to three main sources: (i) partially averaged scalar coupling to neighbouring protons, (ii) intra- or inter-molecular exchange with other $\mathrm{NH}$ or $\mathrm{OH}$ protons, and (iii) partially coalesced coupling to the quadrupolar ${ }^{14} \mathrm{~N}$-nucleus $(I=1)$, which usually has a short $T_{1}$. The formation of hydrogen bonds between PBI and polar solvents is well established but still a topic of lively discussions in the fuel cell community because of the only partial understanding of the dominating mechanism of proton conduction in such polymer membranes. Parallel to the bulk ion transport mechanism (movement of polymer chains), the three dimensional H-bonded network provides a medium in which proton hopping (the Grotthuss mechanism) plays an important role. ${ }^{20,29}$ Our NMR analysis supports the hypothesis of exchange phenomena in polybenzimidazole dissolved in dimethylacetamide: the basic functionality of PBI allows the uptake of acid and both proton donor $(-\mathrm{NH}-)$ and proton acceptor $(-\mathrm{N}=)$ hydrogen bonding sites can exhibit specific interactions with polar solvents and/or other PBI units.

In addition, we consider the chemical behaviour of a simple benzimidazole (BI) molecule dissolved in a generic polar solvent. The exchange phenomena observed above for PBI are correlated to the tautomerism exhibited by $\mathrm{BI}$ and extensively described in the literature. ${ }^{30} \mathrm{~A}$ very fast exchange process of proton $\mathrm{H}_{k}$ occurs between the two nitrogens of the ring. The two possible tautomeric forms would be sterically identical so that positions $\mathrm{i} / \mathrm{j}$ and $\mathrm{c} / \mathrm{h}$ would be chemically equivalent in a monomeric benzimidazole ring. Because of unsymmetric molecular substitutions, the two sites become different, so that separate resonances are detectable in our NMR spectra of the polymeric form of benzimidazole (Fig. 1-3). Nevertheless, in the ${ }^{13} \mathrm{C}$ NMR spectrum of PBI, together with very sharp resonance peaks, three very broad signals at $\sim 140$ and $\sim 115 \mathrm{ppm}$ are identified (Fig. 1b). The formation of hydrogen bonds, with the solvent surrounding the polymer, limits the free dynamics of the tautomeric process and slows down the proton exchange in the imidazole ring. Consequently, using the same reasoning as for the interpretation of NMR signals of the $\mathrm{H}_{k}$ protons, the three broad peaks in the ${ }^{13} \mathrm{C}$ spectrum of Fig. $1 \mathrm{~b}$ were attributed to atomic positions influenced by proton dynamic phenomena. From the NMR spectra, we can determine not only the isotropic chemical shifts, but also derive some conclusions on the dynamic behaviour and coordination of the nuclei involved in the H-bonds on the basis of the chemical shielding effects. Accordingly, the methodology used in our study provides a sensitive probe for the electronic environment and molecular mobility of diagnostic nuclei.

The assignment of the broad NMR peaks to carbons $\mathrm{C}_{i}, \mathrm{C}_{j}$ and $\mathrm{C}_{b}$, is consistent with the presence of two tautomeric forms with different chemical environments for the three carbons. In support to this conclusion is the detection of no broadening for the resonance signals of $\mathrm{C}_{h}$ and $\mathrm{C}_{c}$. It is interesting to note the sharpness of the $\mathrm{C}_{a}$ peak, despite its proximity to the hydrogen bonding sites. $\mathrm{C}_{a}$ is directly bound to both imidazole nitrogens involved in the tautomeric process. Its chemical environment is not affected by the different structures caused by the tautomeric conversion and a very sharp signal at $137.5 \mathrm{ppm}$ is observable.

Finally, to elucidate the proton exchange processes we have carried out temperature-dependent ${ }^{1} \mathrm{H}-\mathrm{NMR}$ studies in the range between 10 and $70{ }^{\circ} \mathrm{C}$. Fig. 4 shows the variation of the proton NMR spectrum of PBI dissolved in DMeAc at five different temperatures. The spectra were normalized with the peak centered at $8.63 \mathrm{ppm}$. An upfield shift of the imidazole $\mathrm{H}_{k}$ proton signal is observed with increase in temperature. The $\mathrm{H}_{k}$ signal is displaced from $13.3 \mathrm{ppm}$ to $13.9 \mathrm{pm}$ as the temperature is increased from 10 to $70{ }^{\circ} \mathrm{C}$. The gradual shift is quantitative as reported in Fig. 5 and shows 


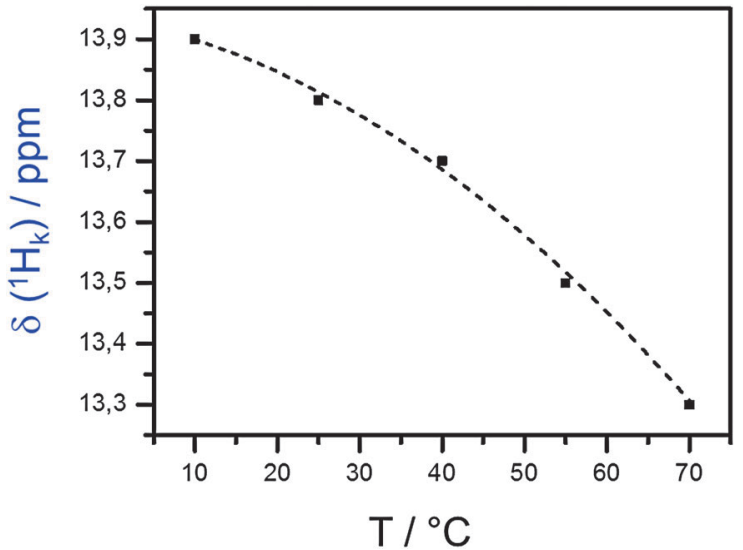

Fig. 5 Dependence of imidazole proton ${ }^{1} \mathrm{H}_{k}$ chemical shift on temperature for $\mathrm{PBI}$ in $\mathrm{DMeAc}$ solution. The line is a guide for the eye only.

a monotonic decrease. For the other proton signals no shift is observable (Fig. 4).

PBI possesses both proton donor (-NH-) and proton acceptor $(-\mathrm{N}=)$ hydrogen bonding sites, which exhibit specific interactions with protic and aprotic polar species. The NMR findings are interpreted in terms of electric dipole moments induced in PBI by the electric field arising from the solvent dipoles and the surrounding PBI chains. Earlier Sannigrahi et al. have shown the conformational transition of PBI chains in phosphoric acid solution with temperature. ${ }^{31}$ At high temperature the aggregated structure of PBI solution breaks and a conformational transition occurs from an extended helical conformer to a collapsed compact coil conformer. $\mathrm{H}_{k}$ is a strong hydrogen-bonding proton and therefore it can be argued that the upfield shift of its signal is due to a disruption of the interchain hydrogen bonding at high temperatures. Similar observation and conclusion were made by Sannigrahi et al. for PBI in DMSO- $d_{6} \cdot{ }^{17}$

In summary, using one and two dimensional NMR methods, we determined the resonance signals of polybenzimidazole in dimethylacetamide. From the shape of some diagnostic peaks, our data support the hypothesis of hydrogen bonding networks between the polymer and the solvent and proton exchange phenomena. The temperature-dependence NMR study gives rise to interesting insights into the intermolecular interactions (interchain hydrogen bonding) between the polymer chains in solution. Finally, the chemical shift assignments provide the spectroscopic basis for a study of the dynamics of certain ${ }^{1} \mathrm{H}$ and ${ }^{13} \mathrm{C}$ resonances. Studies in this direction are in progress.

\section{Experimental section}

PBI was obtained from FuMA-Tech $\mathrm{GmbH}$, St. Ingbert, Germany, and was additionally purified by heating at $150{ }^{\circ} \mathrm{C}$ for 60 min. For NMR measurements, PBI was gradually dissolved in $N, N$-dimethylacetamide (DMAc, purchased from Merck) under a continuous heating process at $120{ }^{\circ} \mathrm{C}$.

All NMR spectra were recorded using a Varian INOVA $400 \mathrm{MHz}$ NMR spectrometer. Chemical shifts are relative to the residual proton signal of the external deuterated solvent, $\mathrm{D}_{2} \mathrm{O}$, used as a reference. For the temperature-dependent measurements a solution of 3-(trimethylsilyl)propanoic acid in $\mathrm{D}_{2} \mathrm{O}$, filled in a capillary, was used as a reference.

\section{Acknowledgements}

F. C. is grateful to the University of Padova for providing the opportunity to spend a research period in the Forschungszentrum Jülich.

\section{References}

1 R. Borup, J. Meyers, B. Pivovar, Y. S. Kim, R. Mukundan, N. Garland, D. Myers, M. Wilson, F. Garzon, D. Wood, P. Zelenay, K. More, K. Stroh, T. Zawodzinski, J. Boncella, J. E. McGrath, M. Inaba, K. Miyatake, M. Hori, K. Ota, Z. Ogumi, S. Miyata, A. Nishikata, Z. Siroma, Y. Uchimoto, K. Yasuda, K. I. Kimijima and N. Iwashita, Chem. Rev., 2007, 107, 3904-3951.

2 F. Conti, E. Negro, V. Di Noto, G. Elger, T. Berthold and S. Weber, Int. J. Hydrogen Energy, 2012, 37, 6317-6325.

3 Y. H. Liu, T. H. Nguyen, N. Kristian, Y. L. Yu and X. Wang, J. Membr. Sci., 2009, 330, 357-362.

4 V. Di Noto, S. Lavina, G. A. Giffin and E. Negro, Electrochim. Acta, 2011, 57, 4-13.

5 J. N. Asensio, E. M. Sánchez and P. Gómez-Romero, Chem. Soc. Rev., 2010, 39, 3210-3239.

6 T. Smolinka, S. Rau and C. Hebling, in Hydrogen and Fuel Cells, ed. D. Stolten, Wiley-VCH, Weinheim, 2010, ch. 13.

7 S. Bose, T. Kuila, T. X. H. Nguyen, N. H. Kim, K. Lau and J. H. Lee, Prog. Polym. Sci., 2011, 36, 813-843.

8 J. T. Wang, R. F. Savinell, J. S. Wainright, M. Litt and H. Yu, Electrochim. Acta, 1996, 41, 193-197.

9 Q. Li, J. O. Jensen, R. F. Savinell and N. J. Bjerrum, Prog. Polym. Sci., 2009, 34, 449-477.

10 J. Hu, J. Luo, P. Wagner, O. Conrad and C. Agert, Electrochem. Commun., 2009, 11, 2324-2327.

11 F. J. Nores-Pondal, M. P. Buera and H. R. Corti, J. Power Sources, 2010, 195, 6389-6397.

12 V. Di Noto, M. Piga, G. A. Giffin, E. Quartarone, P. Righetti, P. Mustarelli and A. Magistris, Phys. Chem. Chem. Phys., 2011, 13, 12146-12154.

13 L. Xiao, H. Zhang, T. Jana, E. Scanlon, R. Chen, E.-W. Choe, L. S. Ramanathan, S. Yu and B. C. Benicewicz, Fuel Cells, 2005, 5, 287-295.

14 A. Sannigrahi, S. Ghosh, S. Maity and T. Jana, Polymer, 2011, 52, 4319-4330.

15 F. Conti, A. Majerus, V. Di Noto, C. Korte, W. Lehnert and D. Stolten, Phys. Chem. Chem. Phys., 2012, 14, 10022-10026.

16 A. Sannigrahi, S. Ghosh, S. Maity and T. Jana, Polymer, 2010, 5929-5941.

17 A. Sannigrahi, D. Arunbabu, R. M. Sankar and T. Jana, Macromolecules, 2007, 40, 2844-2851.

18 N. W. Brooks, R. A. Duckett, J. Rose, I. M. Ward and J. Clements, Polymer, 1993, 34, 4038-4042.

19 T. Kojima, J. Polym. Sci., Polym. Phys. Ed., 1980, 18, 1791-1800. 
20 A. Schechter, R. F. Savinell, J. S. Wainright and D. Ray, J. Electrochem. Soc., 2009, 156, B283-B290.

21 S. Suarez and S. Greenbaum, Chem. Rec., 2010, 10, 377-393.

22 H. Ye, J. Huang, J. J. Xu, N. K. A. C. Kodiweera, J. R. P. Jayakody and S. G. Greenbaum, J. Power Sources, 2008, 178, 651-660.

23 H. A. Every, L. D. Ionescu, M. P. de Heer, Y. Álvarez-Gallego and G. J. M. Janssen, Fuel Cells, 2008, 3-4, 254-261.

24 J. R. P. Jayakody, S. H. Chung, L. Durantino, H. Zhang, L. Xiao, B. C. Benicewicz and S. G. Greenbaum, J. Electrochem. Soc., 2007, 154, B242-B246.

25 C. E. Hughes, S. Haufe, B. Angerstein, R. Kalim, U. Mähr, A. Reiche and M. Baldus, J. Phys. Chem. B, 2004, 108, 13626-13631.
26 E. W. Neuse, Adv. Polym. Sci., 1982, 47, 1.

27 Spectral Database for Organic Compounds, SDBS, http:// riodb01.ibase.aist.go.jp/sdbs/(National Institute of Advanced Industrial Science and Technology, 2012).

28 R. S. Macomber, A complete introduction to modern NMR spectroscopy, John Wiley \& Sons, New York, 1998, ch. 10.

29 K. D. Kreuer, S. J. Paddison, E. Spohr and M. Schuster, Chem. Rev., 2004, 104, 4637-4678.

30 M. B. Smith and J. March, Advanced Organic Chemistry, Wiley Interscience, New York, 2001.

31 A. Sannigrahi, D. Arunbabu and T. Jana, Macromol. Rapid Commun., 2006, 27, 1962-1967. 